\title{
A clinical survey of paraquat formulation workers
}

\author{
J. K. HOW A R D
}

From the Plant Protection Division, ICI Limited, Jealott's Hill Research Station, Bracknell, Berks. RG12 6EY

ABSTRACT A group of 18 male Caucasian workers from the United Kingdom and a further group of 18 male mixed race (mainly Malay) workers from Malaysia employed in the formulation of paraquatbased herbicides were examined for evidence of chronic ill health after long-term exposure to paraquat. Clinical records were examined, medical and occupational histories were obtained and a clinical examination, particularly of the skin, was undertaken. Skin rashes, nail damage and epistaxes were encountered by most workers as a result of direct contact of skin and mucous membranes with paraquat. These conditions subsided rapidly and no worker reported any sequelae. There was no clinical evidence of long-term effects on skin, mucous membranes or general health following exposure to paraquat over several years in these workers.

The bipyridyl herbicide paraquat has been in general use in agriculture since the early 1960 s, but only three surveys of workers using this compound have been conducted since its introduction. The first of these was a carefully monitored trial of spray operators in Malaysian rubber plantations (Swan, 1969) and this was thought to come very close to the extremes of exposure likely to occur in agricultural practice. It was shown that good personal hygiene was sufficient to prevent problems arising from paraquat exposure under normal working conditions. Trials conducted on a Trinidad sugar estate (Hearn and Keir, 1971) drew attention to the risks of nail damage following gross contamination with diluted paraquat, but again there was no evidence of serious untoward reactions to the compound. The most recent study, conducted in the United States (Staiff et al., 1975), also demonstrated the general safety of paraquat under normal working conditions.

Attention has been drawn, by a number of workers, to the acute manifestations of the delayed caustic effect of concentrated solutions of paraquat on skin, nails and eyes (Cant and Lewis, 1968; Joyce, 1969; Samman and Johnson, 1969; Sinow and Wei, 1973; Baran, 1974) and the systemic effects of oral ingestion are well documented (Fletcher, 1974; Kimbrough, 1974; Connolly, 1975). Oral ingestion, however, is unlikely to occur during work. There have been no studies of the possible long-term effects of

Received for publication 23 September 1977

Accepted for publication 11 April 1979 chronic exposure to paraquat over many years, in spite of the exaggerated claims that have been made concerning the dangerous properties of this herbicide and the attendant risks of occupational exposure (Peoples et al., 1977; Fitzgerald et al., 1978). The present study has been undertaken to look specifically at workers with significant and continuous exposure to paraquat for several years, in order to determine whether such workers developed chronic clinical problems, particularly of the skin.

\section{Methods}

POPULATION

Two groups of workers involved in the formulation of paraquat-based herbicides were selected for study. It is generally agreed that workers in the manufacture and formulation of agricultural chemicals are likely to have a greater degree of exposure than those using these chemicals in the field, such as farmers and spray operators, whose exposure is usually intermittent, often infrequent and who also use many types of pesticides making effects difficult to interpret. The first group of workers consisted of 18 men at the ICI Plant Protection Division formulation plant at Yalding in Kent. Eight members of the group had worked only with solid formulations of paraquat involving exposure to dust, seven had handled liquid formulations only and had been faced with problems of spillages and splashes, and three workers had been involved with both types of formulation. The mean age of the group was $44.7 \mathrm{yr}$ (range 
22-61 yr) and the working week was $37 \cdot 5 \mathrm{~h}$ to which may be added a variable degree of overtime, probably about $10 \%$. The length of time from first exposure varied from $1.3 \mathrm{yr}$ to $12.5 \mathrm{yr}$ (mean $5.00 \mathrm{yr}$, SD 3.0).

Partial protective clothing was worn, consisting of overalls, rubber aprons, rubber gloves, rubber boots and caps and face shield or goggles when handling liquid formulations. Overalls, rubber gloves, rubber boots, caps, goggles and an approved dust mask were used by those handling solid formulations.

The second group of workers also consisted of 18 males, in this case from the Chemical Company of Malaysia formulation plant at Kelang, Malaysia. They were of mixed race, mainly Malay with some Indian and Chinese, with a mean age of $29 \mathrm{yr}$ (range 23-39 yr). They were involved only with liquid formulations of paraquat and had a working week of $42 \mathrm{~h}$, with overtime which was again estimated at about $10 \%$. The length of time from first exposure was from $0.5 \mathrm{yr}$ to $6.6 \mathrm{yr}$ (mean $2.3 \mathrm{yr}, \mathrm{SD} 1.6$ ). This group of workers also wore protective clothing of the type outlined above, but in the high ambient temperature and humidity of Malaysia the use of goggles and rubber aprons was frequently neglected and gloves also were commonly not worn.

The details of these two groups are set out in Table 1 and the pattern of exposure in Table 2. The total amount of paraquat ion handled in the two plants per year may be measured in tonnes.

Liquid formulations of paraquat contain either $20 \%$ or $10 \%$ of paraquat ion, together with a variety of wetters and stabilisers. Some formulations also contain other herbicides. Exposure to paraquat is
Table 2 Period since first exposure to paraquat

\begin{tabular}{|c|c|c|c|c|c|c|}
\hline \multirow{2}{*}{$\begin{array}{l}\text { Total period } \\
\text { of exposure } \\
\text { to paraquat }\end{array}$} & \multicolumn{2}{|l|}{ Yalding } & \multicolumn{2}{|l|}{ Kelang } & \multicolumn{2}{|l|}{ Total } \\
\hline & $\begin{array}{l}\text { No. of } \\
\text { workers }\end{array}$ & $\begin{array}{l}\% \text { of } \\
\text { group }\end{array}$ & $\begin{array}{l}\text { No. of } \\
\text { workers }\end{array}$ & $\begin{array}{l}\% \text { of } \\
\text { group }\end{array}$ & $\begin{array}{l}\text { No. of } \\
\text { workers }\end{array}$ & $\begin{array}{l}\% \text { of } \\
\text { group }\end{array}$ \\
\hline $\begin{array}{l}>10 \mathrm{yr} \\
8-10 \mathrm{yr} \\
5-7 \mathrm{yr} \\
3-5 \mathrm{yr} \\
<3 \mathrm{yr}\end{array}$ & $\begin{array}{l}1 \\
3 \\
3 \\
8 \\
3\end{array}$ & $\begin{array}{r}5 \cdot 5 \\
16 \cdot 7 \\
16 \cdot 7 \\
44 \cdot 4 \\
16 \cdot 7\end{array}$ & $\begin{array}{r}- \\
1 \\
7 \\
10\end{array}$ & $\begin{array}{l}- \\
-5.5 \\
38.9 \\
55.6\end{array}$ & $\begin{array}{r}1 \\
3 \\
4 \\
15 \\
13\end{array}$ & $\begin{array}{r}2 \cdot 8 \\
8 \cdot 3 \\
11 \cdot 1 \\
41 \cdot 7 \\
36 \cdot 1\end{array}$ \\
\hline Totals & 18 & $100 \cdot 0$ & 18 & $100 \cdot 0$ & 36 & $100 \cdot 0$ \\
\hline
\end{tabular}

most likely to occur in charging the system or at filling out, or when a blockage in the system is cleared. The solid formulations of paraquat contain $2.5 \%$ of paraquat ion (plus $2.5 \%$ diquat) and exposure was highest when freshly produced granules were removed from the drying trays. Considerable amounts of dust are produced in the drying process and in the early days of formulation the level of housekeeping was not always satisfactory. This problem has been overcome by enclosure of the formulation process and extraction ventilation at the filling out where sachets are automatically filled and sealed.

\section{SUR VEY}

The medical records of both groups of workers were examined. These record all significant episodes of ill health, sickness absence and any accidents or injuries. The medical staff of the plant used a questionnaire which included previous employment history, exposure to other pesticides, past medical

Table 1 Details of UK and Malaysian work groups

\begin{tabular}{|c|c|c|c|c|c|c|c|c|}
\hline \multirow[t]{2}{*}{ Subject } & \multicolumn{4}{|c|}{ Yalding work-force } & \multicolumn{4}{|c|}{ Kelang work-force } \\
\hline & $\begin{array}{l}\text { Age } \\
(y r)\end{array}$ & Ethnic group & $\begin{array}{l}\text { Total period of } \\
\text { exposure to } \\
\text { paraquat } \\
(y r)\end{array}$ & Formulation & $\begin{array}{c}\text { Age } \\
(y r)\end{array}$ & Ethnic group & $\begin{array}{l}\text { Total period of } \\
\text { exposure to } \\
\text { paraquat } \\
(y r)\end{array}$ & Formulation \\
\hline 1 & 22 & Caucasian & $1 \cdot 3$ & $\mathbf{S}$ & 39 & Malay & 0.5 & $\mathbf{L}$ \\
\hline 2 & 23 & Caucasian & $2 \cdot 0$ & $\mathbf{S}$ & 30 & Chinese & $1 \cdot 0$ & $\mathbf{L}$ \\
\hline 3 & 43 & Caucasian & $2 \cdot 5$ & $\mathbf{S}$ & 27 & Malay & $2 \cdot 0$ & $\mathbf{L}$ \\
\hline 4 & 24 & Caucasian & $3 \cdot 0$ & $\mathbf{S}, \mathbf{L}$ & 32 & Malay & $2 \cdot 0$ & $\mathbf{L}$ \\
\hline 5 & 49 & Caucasian & $3 \cdot 0$ & $\mathbf{S}$ & 30 & Indian & $3 \cdot 0$ & $\mathbf{L}$ \\
\hline 6 & 43 & Caucasian & $3 \cdot 0$ & $\mathbf{L}$ & 33 & Indian & $3 \cdot 0$ & $\mathbf{L}$ \\
\hline 7 & 46 & Caucasian & $3 \cdot 0$ & $\mathbf{L}$ & 24 & Indian & 0.5 & $\mathbf{L}$ \\
\hline 8 & 51 & Caucasian & $4 \cdot 0$ & $\mathbf{S}$ & 37 & Malay & $3 \cdot 0$ & $\mathbf{L}$ \\
\hline 9 & 55 & Caucasian & $4 \cdot 0$ & $\mathbf{L}$ & 34 & Chinese & 3.0 & $\mathbf{L}$ \\
\hline 10 & 61 & Caucasian & $4 \cdot 0$ & $\mathbf{S}, \mathbf{L}$ & 24 & Malay & 0.6 & $\mathbf{L}$ \\
\hline 11 & 49 & Caucasian & $5 \cdot 0$ & $\mathbf{S}$ & 23 & Malay & $3 \cdot 5$ & $\mathbf{L}$ \\
\hline 12 & 27 & Caucasian & $3 \cdot 5$ & $\mathbf{S}$ & 23 & Malay & $4 \cdot 0$ & $\mathbf{L}$ \\
\hline 13 & 58 & Caucasian & $5 \cdot 0$ & $\mathbf{L}$ & 23 & Malay & $1 \cdot 25$ & $\mathbf{L}$ \\
\hline 14 & 48 & Caucasian & $7 \cdot 0$ & $\bar{L}$ & 28 & Indian & $4 \cdot 0$ & $\mathbf{L}$ \\
\hline 15 & 55 & Caucasian & $8 \cdot 0$ & $\mathbf{S}, \mathbf{L}$ & 27 & Malay & 0.6 & $\mathbf{L}$ \\
\hline 16 & 61 & Caucasian & $8 \cdot 0$ & L & 32 & Malay & 0.5 & $\mathbf{L}$ \\
\hline 17 & 29 & Caucasian & $10 \cdot 0$ & $\overline{\mathbf{L}}$ & 31 & Malay & 2.0 & $\mathbf{L}$ \\
\hline 18 & 60 & Caucasian & $12 \cdot 5$ & $\overline{\mathbf{S}}$ & 26 & Malay & 6.5 & $\overrightarrow{\mathbf{L}}$ \\
\hline
\end{tabular}


Table 3 Incidence of clinical signs and symptoms in all workers

\begin{tabular}{|c|c|c|c|c|c|c|}
\hline \multirow[t]{2}{*}{ Formulation } & \multicolumn{2}{|c|}{ Yalding group } & \multicolumn{2}{|c|}{ Kelang group } & \multicolumn{2}{|l|}{ Total } \\
\hline & Number & $\%$ of group & Number & $\%$ of group & Number & $\%$ of total \\
\hline Liquid formulations only & \multicolumn{2}{|c|}{$\mathbf{n}=7$} & \multicolumn{2}{|c|}{$\mathrm{n}=18$} & \multicolumn{2}{|c|}{$\mathbf{n}=25$} \\
\hline Acute skin rashes & $\mathbf{0}$ & 0 & 9 & 50 & 9 & 36 \\
\hline Nail damage & 2 & $28 \cdot 6$ & 1 & $5 \cdot 5$ & 3 & 12 \\
\hline Epistaxis & 1 & $14 \cdot 3$ & 2 & $11 \cdot 1$ & 3 & 12 \\
\hline Eye injuries & 0 & 0 & 6 & $33 \cdot 3$ & 6 & 24 \\
\hline Blepharitis & $\mathbf{0}$ & $\mathbf{0}$ & 1 & $5 \cdot 5$ & 1 & 4 \\
\hline Delayed healing & 0 & 0 & 1 & $5 \cdot 5$ & 1 & 4 \\
\hline No complaints & 4 & $57 \cdot 1$ & 3 & 16.6 & 7 & 28 \\
\hline Solid formulations only & \multicolumn{2}{|c|}{$\mathbf{n}=\mathbf{8}$} & & & \multicolumn{2}{|c|}{$n=8$} \\
\hline Nail damage & 3 & $37 \cdot 5$ & & & 3 & $37 \cdot 5$ \\
\hline Epistaxis & 7 & $87 \cdot 5$ & & & 7 & $87 \cdot 5$ \\
\hline Blepharitis & 1 & $12 \cdot 5$ & & & 1 & $12 \cdot 5$ \\
\hline Delayed healing & 1 & $12 \cdot 5$ & & & 1 & $12 \cdot 5$ \\
\hline No complaints & 0 & 0 & & & $\mathbf{0}$ & 0 \\
\hline Both liquid and solid formulations & & $=3$ & & & & \\
\hline Nail damage & 2 & $66 \cdot 6$ & & & 2 & 66.6 \\
\hline Epistaxis & 2 & $66 \cdot 6$ & & & 2 & 66.6 \\
\hline Blepharitis & 1 & $33 \cdot 3$ & & & 1 & $33 \cdot 3$ \\
\hline Delayed healing & 2 & $66 \cdot 6$ & & & 2 & $66 \cdot 6$ \\
\hline No complaints & $\mathbf{0}$ & $\mathbf{0}$ & & & $\mathbf{0}$ & $\mathbf{0}$ \\
\hline
\end{tabular}

$\mathbf{n}=$ no. of workers.

history (concentrating particularly on any history of skin, respiratory tract or gastrointestinal conditions) together with smoking habits and other addictions. The clinical examination was directed particularly towards any evidence of chronic skin conditions.

\section{Results}

The incidence of clinical problems associated with exposure to paraquat is set out in Table 3 . The occurrence of numerous episodes resultant upon direct contact with paraquat indicates a significant degree of exposure in both groups of workers.

There were a number of acute skin rashes, burns and eye injuries at the Kelang plant and this may reflect the lower level of safety consciousness among the Malaysian workers. Skin contact with paraquat usually produced a delayed caustic effect, consisting of erythema with occasional formation of bullae. In most cases healing was normal, although in one case with severe scrotal inflammation through careless spillage of paraquat concentrate, healing took over two weeks. Eye splashes were followed by intense conjunctivitis with blepharospasm and lacrimation. In none of these cases, however, was there any evidence of permanent damage to skin, conjunctivae or cornea, nor was vision impaired in any case.

The particular problem among the workers handling solid formulations was the occurrence of occasional epistaxes. In only one case, however, was this sufficiently persistent to necessitate removal of the worker from further exposure. In the majority of cases the phenomenon was encountered within the first week or so of working with the solid formula- tion; thereafter the incidence of epistaxes fell off rapidly. In no case was there frank bleeding and the invariable complaint was of frequent spotting of the handkerchief with blood after blowing the nose.

The only possibly chronic effects were the occasional complaints of blepharitis and the phenomenon of delayed healing. Blepharitis was reported by only three of the 36 workers and in each case it was very mild. Symptoms subsided rapidly after removal from work. Delayed healing was seen as a failure of small lacerations and abrasions to heal spontaneously in the usual time. Small wounds tended to remain open for several days with the increased risk of infection. Only four of the workers complained of this problem, three of whom had handled the solid formulations. The problem resolved as soon as the worker was removed from exposure to paraquat; the condition appears to be a function of skin contamination and, as such, probably reflects lack of personal hygiene.

Examination of the skin of all workers provided no evidence of the development of chronic skin conditions following exposure to paraquat. Hyperkeratosis has been described following exposure (Murphy, 1975), but none of these two groups of workers showed any evidence of this type of lesion, nor did they show any eczematous lesions. No allergic type rashes were found, nor was there any history among these workers of allergic manifestations to paraquat.

There was no other clinical evidence of chronic ill health among these men following prolonged exposure to paraquat, nor did any of them attribute any illness, apart from the acute episodes, to their work. 


\section{Discussion}

Paraquat has been blamed for a wide variety of clinical manifestations. The report of Peoples et al. (1977) records such symptoms as dizziness, paraesthesiae, chest pains, nausea, diarrhoea, general weakness and malaise following minimal exposure. Such symptoms are very non-specific and do not relate to what is known of the effects of paraquat poisoning, but are very much the pattern of symptoms found in anxiety states. It is not unreasonable to assume that such a cause was responsible and this pattern of symptoms might be termed the 'paraquat fear' syndrome. None of these symptoms was recorded in any of the workers from the two formulating plants who had been exposed to paraquat continuously for varying periods of up to $12.5 \mathrm{yr}$. The only clinical manifestations among the formulation workers were the local effects caused by direct contact of paraquat on skin or mucous membranes, which are well documented. The important point is that such direct contact over many years did not give rise to any systemic effects and there has been no evidence of any sequelae among any of the workers, nor has the work force attributed any health problems to such exposure.

The local effects of paraquat underline the necessity for careful handling of this herbicide, as would be the case with any caustic material, but local lesions heal with no permanent after-effects. The experience of both groups of workers in this study suggests that paraquat is unlikely to give rise to either chronic skin complaints or systemic effects under normal conditions, even when handled for many years.

\section{References}

Baran, R. L. (1974). Nail damage caused by weedkillers and insecticides. Archives of Dermatology, 110, 467.

Cant, J. S., and Lewis, D. R. H. (1968). Ocular damage due to paraquat and diquat. British Medical Journal, 2, 224.

Connolly, M. E. (1975). Paraquat poisoning-clinical features. Proceedings of the Royal Society of Medicine, 68, 441.

Fitzgerald, G. R., Barniville, G., Black, J., Silke, B., Carmody, M., and O'Dwyer, W. F. (1978). Paraquat poisoning in agricultural workers. Journal of the Irish Medical Association, 71, 336-342.

Fletcher, K. (1974). Paraquat poisoning. In Forensic Toxicology, pp. 86-98. Edited by B. Ballantyne. John Wright: Bristol.

Hearn, C. E. D., and Keir, W. (1971). Nail damage in spray operators exposed to paraquat. British Journal of Industrial Medicine 28, 399-403.

Joyce, M. (1969). Ocular damage caused by paraquat. British Journal of Ophthalmology, 53, 688-690.

Kimbrough, R. D. (1974). Toxic effects of the herbicide paraquat. Chest, 65, (Suppl.) 61S-62S

Murphy, S. D. (1975). Pesticides. In Toxicology: The Basic Science of Poisons, p. 439. Edited by L. J. Casarett and J. Doull. Macmillan: New York.

Peoples, S. A., Maddy, K. T., and Riddle, L. C. (1977). Human Health Problems Associated with the Herbicide Paraquat in California-1965-1976. Report No. ACF 59-314. Agriculture, Chemicals and Feed, Department of Food and Agriculture, California.

Samman, P. D., and Johnson, E. N. M. (1969). Nail damage associated with handling paraquat and diquat. British Medical Journal, 1, 818-819.

Sinow, J., and Wei, E. (1973). Ocular toxicity of paraquat. Bulletin of Environmental Contamination and Toxicology, 9, 163-168.

Staiff, D. C., Comer, S. W., Armstrong, J. F., and Wolfe, H. R. (1975). Exposure to the herbicide paraquat. Bulletin of Environmental Contamination and Toxicology, 334-340.

Swan, A. A. B. (1969). Exposure of spray operators to paraquat. British Journal of Industrial Medicine, 26, 322-329. 